\title{
On the Rationality of Traditional Akan Religion: Analyzing the Concept of God
}

\author{
Hasskei M. Majeed \\ Lecturer, Department of Philosophy and Classics, \\ University of Ghana, Legon
}

\begin{abstract}
This paper is an attempt to show how logically acceptable (or rational) belief in Traditional Akan religion is. The attempt is necessitated by the tendency by some scholars to (mis) treat all religions in a generic sense; and the potential which Akan religion has to influence philosophical debates on the nature of God and the rationality of belief in God - generally, on the practice of religion. It executes this task by expounding some rational features of the religion and culture of the Akan people of Ghana. It examines, in particular, the concept of God in Akan religion. This paper is therefore a philosophical argument on the sacred and institutional representation of what humans have come to refer to as "religious."
\end{abstract}

Keywords: rationality; good; Akan religion; God; worship

By "Traditional Akan religion," I mean the indigenous system of sacred beliefs, values, and practices of the Akan people of Ghana ${ }^{1}$. This is not to say, however, that the Akans are only found in Ghana. Traditional Akan religion has features that distinguish it from other African religions, and more so from non-African ones. This seems to underscore the point that religious practice varies across the cultures of the world, although all religions could share some common attributes. Yet, some philosophers and religionists, for instance, have not been measured in their presentation of the general features of religion. The danger in doing this is that such philosophers and religionists risk coming across as scholars who are either unaware of the nuances of religion or overlook them. While, for instance, Jarvie and Agassi (1977) and Horton (1960)

1. In this essay, I will refer to indigenous Akan religion as "Traditional Akan religion" - but not as "traditional Akan religion". This is because starting it with a capital letter makes it fall in line with the way the names of the other religions mentioned in this essay are written. Wole Soyinka's "The burden of memory, the muse of forgiveness" (2014) underscores the equality of all religions. 
generalize their findings on Western culture to cover all religions, Abioje, an African religionist, generalizes his observations on Yoruba religious thought to constitute the position of Traditional African thought. By each of these generalizations, the rationality of Traditional Akan religion would be affected. For, the argument of Jarvie and Agassi and Horton ultimately points to the irrationality of all religions (of which the Traditional Akan religion is one); and that of Abioje exposes Akan religion, being an African religion, to the charge of irrationality as leveled by Jarvie and Agassi and Horton. But, a careful examination of contemporary literature, including those of the above mentioned scholars, reveals how shaky the arguments of the two generalizing parties are - especially, if the question of the possible irrationality of Akan religion is considered. I begin with the argument of the former.

Some Western philosophers, such as Jarvie and Agassi (1977, p. 174), purport to ascribe "partial" rationality to all religions, while another Western philosopher, Horton (1960, p. 222) strips them off all rationality altogether. Jarvie and Agassi explain their position this way:

... let us attribute rationality to an action if there is a goal to which it is directed; let us attribute rationality to a belief if it satisfies some standard or criterion of rationality which has been adopted, such as that it is based on good evidence, or is beyond reasonable doubt, or is held open to criticism, etc. (Jarvie \& Agassi, 1977, p. 173)

They therefore consider "the goal of religious actions as rational" because it includes "something like the worship of God, or the exorcism of sin, or the survival of life after death" (Jarvie \& Agassi, 1977, p. 174). Nevertheless, they "maintain that religion defies most criteria of rational belief" and as such religious beliefs are irrational (Jarvie \& Agassi, 1977, p. 174).

However, since religious actions, including those of the Akans, can hardly be devoid of any religious beliefs at all, it is difficult to see how Jarvie and Agassi's apparent awarding of rationality to actions can absolve religion of the charge of irrationality. For religious beliefs are conceived by them as some sort of dogmas. Indeed, the other-worldly expectations of practitioners of Christianity, as well as the supernatural, superhuman origins of Christian tenets, have all contributed to the emergence of the idea of the alleged irrationality of Christianity and religion (in general). 
These aspects of religion are not only taken as instances of unquestioning acceptance of beliefs among religious followers, but are also regarded as containing beliefs that are not beyond reasonable doubt. Religion is also seen, as in the thesis of Horton (1960, p. 222), to thrive on faith because human reason cannot justify it.

The above conceptions of religion, assuming they were right, would not really apply to Traditional Akan religion. While recognizing the fact that Akan religion postulates the existence of spiritual entities, it differs substantially from Christianity. In Akan culture, for instance, the source of religion is traced to the human being. He was not asked by any metaphysical, higher being to worship or practise religion. Regarding how Akans came to practise their religion and why they expect others to see the need to do same, Gyekye (1996, p. 5) observes that, according to the traditional Akan thinkers,

the human being, irrespective of the culture to which he or she belongs, is essentially a religious being who will, sooner or later, come to see himself or herself as a created being and to appreciate the need not only to look for his or her creator but also to depend on the omnipotence and bounty of that creator... When man sees himself as a created being, he infers that there must be a creator worthy of worship and adoration. Traditional African religion is, thus, a natural religion, independent of revelation.

There are many logical conclusions that can be drawn from this perspective on the origin of religious beliefs or ideas. It can be said that traditional Akan sages have a clear view of the world, a world in which the human being only occupies a part, for, the need to depend on the omnipotence and bounty of the creator, and the idea of being a created being would not have come to him if he was not convinced in any way that he only has control, power, knowledge, and ability over some things and events, while he has virtually no control over other events or existents that lay beyond - the capabilities and knowledge of - humans. In addition to this, it is evident that traditional Akan thinkers adopted what in Western thought, is referred to as Creationism - the belief that the world and things in it were substantially created as they are by a Supreme Being - to postulate the existence of a worshippable Supreme Being. ${ }^{2}$ So, if all this logical reasoning went into the discovery of religious beliefs by these thinkers, then, it may not be correct to

2 The reasons offered in this paragraph are more comprehensive and, thus, better account for worshippability of the Akan God than the account that will be given by Danquah in the next section. 
make the categorical statement that religion is illogical. Indeed, the Akan thinkers will take exception to Benjamin Franklin's (Jarvie \& Agassi, 1977, p. 175) rejection of religion because it is, to him (Franklin), irrational, in the same way as he (the Akan thinker) will contest Horton's comment that religion is founded on faith and not on reason. For, he (Horton) suggests, reason supports science, the claims of which are observable or "testable" (1960, p. 222). Similarly, the Akan attitude toward religion contrasts with the Western orientation revealed by Jarvie and Agassi that "in our society it is no longer controversial to regard religion as irrational; indeed, few people these days bother to claim that religion is rational..." (Jarvie \& Agassi, 1977, p. 174).

The main problem with Pius Abioje's argument is that it erroneously draws Akan religion into the realm of "revelation" and possible irrationality - irrationality as conceived by the former group. Abioje is not the first person to argue that, generally, Traditional African religion is revealed; but he is most probably the first to offer the sort of reasons (to be explained below) in support of that argument. He is therefore singled out for discussion in this paper because (i) analyzing these (new) reasons for the revealed argument is crucial for the understanding of Traditional African religion(s), (ii) doing (i) above will show how generalizing about African religions does not always work, and (iii) his arguments have some implications for the rationality of Traditional African religion(s), including the Akan which is also the subject of this paper. Abioje discusses the general features, common characteristics, of African religions - as a result of which he speaks of the religions in a singular sense. Consequently, I will adopt this singular sense in my discussion or critique of his views.

Although current discourses on Traditional African religion appear to have abandoned the discussions on whether or not the subject of their study is revealed, some contemporary scholars have seen the need to revisit the debate (on the origin of Traditional African religion) with the view to either introducing fresh perspectives to the issue or correcting past ideas. As recently as 2007, Pius Abioje made such an attempt with his publication in the Legon Journal of the Humanities. Therefore, a critique of his views, in the context of examining current opinions on Traditional African religion, is tantamount to addressing a contemporary problem regarding African thought.

Abioje attempts to compare aspects of Traditional African, Islamic, and Christian teachings, and makes recommendations that should lead to mutual respect between these religions. He also argues for the existence of shared human values, stressing that "Human beings can always learn from one another, generally speaking, if there is humility and openness of mind" (Abioje, 2007, p. 156). However, there are serious factual and logical problems regarding the generalization which he makes of his findings on Traditional Yoruba religion to cover Africa. Of interest to this paper are those that portray all African religions as revealed, especially after observing above that such a portrayal, if accurate, would make an African religion like the Akan to be regarded by some philosophers as 
irrational. Here are a few examples. He argues that Traditional African religion is revealed because of a number of reasons. He suggests, first, that since a myth can be understood as "a sacred tradition or primordial revelation [that has] ... some lessons to teach, beyond the material detail," Traditional African religion must be a revealed religion because there are myths - some of which relate to God - in traditional African thought (Abioje, 2007, p. 150).

It is not clear why Abioje should find this sense of revelation a good basis to suggest the revelation of Traditional African religion, especially, given the fact that he also shares S. O. Oso's view that African myths are "the mental efforts of African ancestors to interpret the various cosmological and biological phenomena that they experienced" (Oso, 1979, p. 22). In the instance where an experience-based religious truth or knowledge is described by religionists as having been "revealed naturally", the suggestion has been that such a truth was acquired through the observation of nature. They sometimes call this "general revelation". But, even in this context, the description of the experience as "revealed" could be quite misleading. For, the truth did not "impose" itself as such on the person. Rather, the world (the given world) was made sense of by the person, and subsequently thought of by him/her as leading to some religious truth. After all, subjects or individuals could come to different conclusions upon observing what is largely the same thing. It can, therefore, be maintained that the natural world does not necessarily "reveal" religious truths, since (for instance) it does not necessarily lead one to either the belief in the existence of God or to the practice of religion. One only comes to postulate nature-related religious truths on the basis of one's own reflections, but not because there is a raw "revealed" world. This is consistent with Oso's remark which effectively makes "revelation" alien to African thought. Natural religion is a creation of the human being that derives from the secondary activity of reflection - reflection on the natural world. This point, however, contrasts with what is often called "special revelation", according to which God reveals His religion and prophesies to some special or chosen individuals. It is in this latter sense that religion can properly be described as "revealed", a description which has made some to criticize religion as irrational. The term "revealed religion", as just argued, does not make much sense in the context of "natural religion" because nature does not contain religion, let alone reveal it to humans. Humans rather construct natural religion.

What is needed by Abioje, therefore, to establish that Traditional African religion is a revealed one - something he unsuccessfully attempts to do - is any strong evidence that would suggest that God revealed His religion to our forebears. If African myths (which are not always religious) teach lessons, then they are the direct result of the good quality of reflection done by our forebears on certain recondite concepts. For sure, myths disclose the thoughts of their holders but do not necessarily show that those holders are "spoken to" or revealed to by a Deity in the sense in which religion is often criticized. 
Therefore, to attribute "revelation" to Traditional African religion smacks of an attempt to superimpose an alien concept on African thought.

Abioje's conviction that Traditional African religion is revealed can also be seen in his suggestion that adherents of that religion live by the revealed wishes of God. In this respect, he paraphrases E. B. Idowu (1977) and S. O. Oso (1979) as follows: "in man's earthly life, he is in the hand of the Deity, and to live a good real life, the behests of the Deity must be fulfilled" (Abioje, 2007, p. 149). Of course, God is regarded in traditional thought as good. However, it is quite consistent and even more plausible to argue of the originators of this religion as having not received a sort of catalogue of dos and don'ts from God, but rather that they might have expected the good God, conceived as interested in the well-being of His creatures, to also prefer good human actions, especially those that enhanced the welfare of humans. This exposition also means that the adherents of Traditional African religion did, as they still do, determine good human actions without having to receive any revelation; and that, they have always cherished actions or lifestyles founded on sound moral principles, not because those actions or lifestyles are the commandments of God. Consequently, life on earth, to the practitioners, cannot be fulfilling because it is at the behest of God, but because the actions are motivated by goodness. It may well be that the problems with Abioje's thesis have to do with the way he interpreted his sources and, indeed, the generalization of his findings on Yoruba religion as wholly applicable to Traditional African religion.

This paper will, henceforth, discuss the Akan concept of God, and then the rationality of Akan religion as contained in some wise Akan sayings. The choice of wise sayings is dictated by the need to tap directly into traditional philosophy which is sometimes found in maxims.

\section{The Concept of God in Traditional Akan Thought}

Here, I intend to analyze Akan expressions for God, and discuss the rationality of arguing that His goodness should lead to His being "worshipped." I will also look at whether or not He is personal. All this is to help clarify the Akan concept of God.

In the Akan language, God is referred to as Onyankopon (Nyankopon) or Onyame (Nyame). Beside these, He has several appellations that seek to convey traditional ideas about His nature, works and potency. An example is Jbəadee (Creator, Creator of all things) which also contains the notion of a potent God - since He must logically be potent (indeed, omnipotent) to be able to create all things. Onyankopon and Onyame are often used interchangeably, although some Akan thinkers have sought to distinguish between them. Danquah, for example, has suggested that in a primal sense of God (as "Great Ancestor" of humans), God is referred to as Onyame (Danquah, 1968, p. 27 and p. 152). But the concept of Onyankopon (the "Nana of Ultimate Reality"), in his view, suggests 
more greatness. He further posits that above Onyankopon, is the notion of Jdomankoma which expresses the idea of the Final God (Danquah, p. 152).

Danquah distinguishes between Onyame and Onyankopon in terms of constitution. The former, according to him, is "feeling" or a "feeling entity" with Onyankopon as its metaphysical or intellectual goal (1968, p. 141). Therefore, relating feeling (or Onyame) to sunsum and insight (or Onyankopon) to "okara"3 (understood as "destiny"), Danquah makes Onyankopsn "the greater actualization, or deeper meaning or the intent of Onyame" since "Onyankopon (sic.) is the Okara of Onyame" (1968, p. 141). Although Onyankopon is placed higher by Danquah, He is not deemed to be entirely different from Onyame, in spite of his conviction that they are conceptually separable. The Akan, he explains,

conceived Nyankopon as not being absolutely bereft of all the primitive nature that had attached to Onyame. Onyankopon, too, is feeling. But feeling of a certain active mind, what, at a higher remove, is called conation, or will; namely, an attitude of mind involving a tendency to take action. Again, the Akan conceived of Onyankopon as having the new and additional character of intuition or insight, the intellectual capacity that only an Okara other than Sunsum can possess (Danquah, p. 147).

This seems to suggest that the insight and activity of God unite sunsum and skra in the concept of Onyankopon. Secondly, it is apparent that Onyankopon should have a logical connection with the more abstract Jdomankoma. For although Jdomankoma in itself is Soul, an "Ideal" (Danquah, 1968, pp. 67-68) and devoid of experience, for Him to be an "experiencing being" and be known or experienced by humans (Danquah, pp. 67-68), He must do so through Onyankopon who, according to Danquah, embodies both experience and Ideal ("sunsum" and "okara") (pp. 68-69). The element of experience in Jdomankoma is, or is supplied by, Onyankopon. This, logically, seems to be his main reason for putting forward Onyankopon as a concept ultimately receptive of the other two: that "In the conception of Onyankopon as both Sunsum and Okara, the primal Onyame and the final Odomankoma have a reconciliation" (Danquah, p. 152). For Danquah, "this dual nature of Onyankopon comes to us under two modes: (1) the conception of him as

\footnotetext{
${ }^{3}$ In Akan language, the soul is referred to as skra. Danquah's reference to it as "okara" appears to make possible a link between the ancient, black Egyptian $k a$ (soul) and the Akan soul, since $k a$ is contained in "o-ka-ra."
} 
the Okara of Onyame, and (2) the conception of him as the Sunsum of Odomankoma" (p. 147).

From the above, I make just two observations. First, that perhaps, the centrality of the concept of Onyankopon in understanding the Akan doctrine of God - even in such a divisionist thesis as Danquah's - explains why Onyankopon is an acceptable translation for the word "God." Secondly, in Akan thought, the metaphysical ideas of the skra (soul) and sunsum (spirit; or activity [according to Danquah]) together suggest fundamental existence. In this sense, the physical side of any being is distinguished from its core, metaphysical component. The latter is sometimes spoken of in separate ways (as in sunsum and $\lrcorner k r a$ ) or as one entity (as $\lrcorner k r a$ which, in any case, is a spiritual entity - hence, a sunsum). The human example of this point is articulated by Gyekye (1995, p. 98). But this also means that sunsum is probably the most basic, essential element of all experiencing or existing beings. Accordingly, if Danquah identifies Onyame with sunsum, then it could imply that Onyankopon and Jdomankoma cannot be conceived without Onyame. Onyame, therefore, is the essential identity of God who, in a more comprehensive form, is Onyankopon. These two names, unlike, Jdomankoma, capture the heart of the ontology of God - for, they convey to us God's basic identity as a metaphysical being who experiences and can be experienced. But if, as Danquah notes, the "deeper meaning" of Onyame is Onyankopon, then, it is not surprising that Akan thinkers use the two names interchangeably. In this paper, I adopt the same approach of using the two names interchangeably.

Onyankopsn is seen in Akan thought as good and "identified with goodness itself" (Gyekye, 1996, p. 9). Hence, Onyankopon is not only a desirer of goodness, but also a doer of good. Danquah's understanding of the word "good" appears to capture sufficiently the latter half of the preceding statement. For, his understanding of it is instrumental. That is to say, he advances that to be good is to do good. As he puts it, "Goodness implies value of something done", and that "Onyankopon's doing is good" (Danquah, 1968, p. 152). Therefore, if it is said that "Onyankopon is good" or is "the Supreme Good," it means that He is "the Akan God of Beneficence, practical content of moral life" (Danquah, p. 152). This practical usefulness of Onyankopon seems to Danquah to call for some reciprocal action from the Akan. Indeed, in the immediate consequence to this presentation of the practical conception of the goodness of God, Danquah rhetorically asks: "Why should he (Onyankopon) not be worshipped?" (Danquah, pp. 152-153).

But the question that some philosophers would ask here is: "Why should Onyankopon be worshipped as a result of His supreme goodness to the human being? How much, if it does at all, should God's being supremely good count in His being an object of worship? If these questions are understood in the manner discussed by Socrates in the Euthyphro, then, it could be said that being good to humans does not call for the 
worshipping of the good-doer. Socrates pointed out how the gods' goodness to humans in exchange for worship amounted to a form of barter - and thus not morally worthy. For a morally worthy action is the one performed in expectation of no goods. It appears, then, that the more intelligent and morally aware a being is, the more dishonorable it would be for that being to engage in this trade-off. God is conceived of in Akan thought as supremely moral and rational. As such, it would not be appropriate, on Socratic grounds, to ascribe worshippability to Him on the basis of His goodness or, worse still, supreme goodness to humans.

However, this unjustified correlation between goodness or supreme goodness and worship could mislead one into attributing worshippable status, even if at a lower level, to some non-human agents of goodness. Ancestors are an example. They are believed in Akan thought to be good to the living. It is held that they promote the well-being of the community by enforcing morality and, also, "helping" or "blessing" those who "obey the laws and customs and fulfil their obligations" (Busia, 1954, p. 201). In doing this, the ancestors "see to it that the crops of such people are plentiful, that children are born to them and that their undertakings prosper" (Busia, p. 201). Yet, many Akan philosophers, including Gyekye (1996, p. 161), have argued that the ancestors are not worshipped. This implies that in a case where a worshipped being is deemed to be good, more is required than goodness or supreme goodness to justify the being's worshippability.

It is appropriate here to emphasize the need to treat the question of the "worshipping" of God with caution, since, if not well explained, "worship" might not apply to Traditional Akan religion. Unlike, say, in Christianity where "worship" could mean a religious service to God, Onyankopon is not in this way worshipped. For, Onyankopon does not have any religious service that is performed in His honour. What comes close to being a religious service is the gathering of the people in celebration of religious festivals or landmarks. But even here, the gathering (usually, annually) is often in celebration of the benefits of those events to the people, and to acknowledge the role believed to have been played by the community's deity ("lesser god") and ancestors in their achievement. The deity is conceived of as an intermediary between Onyankopon and the people, but such gatherings as mentioned above are neither in the absolute "service" of the deity nor Onyankopon.

Nonetheless, if by "worship," the intended objective is the showing of veneration or devotion to a supernatural being, then this applies to Onyankopsn. From the foregoing, it would be wrong to describe practitioners of Traditional religion as "worshippers of deities (or lesser gods)". By parity of reasoning, the reference to Traditional religion by many Akan speakers - having been most probably influenced by Christian teachings - as abosonsom (literally, "the-lesser-god or fetish religion") does not appear to capture very well the Akan situation. Secondly, even though the word som is commonly translated as: 
1. "to serve" - for instance, "the girl will serve this nation very well" is rendered in Akan as abaayewa no besom oman yi yie,

2. "to worship" (as in attending religious service) - the statement "Christians meet on Sundays to worship God" is translated as Kristofor hyia Kwasiadabiara som Nyame,

3. "religion" - "Christian religion" is literally translated as Kristosom,

translations 2 and 3 have to be carefully looked at. On the basis of the initial discussion of "worship" and the Akan culture, it can be inferred that translation 2 is not part of Akan sacred practices. Likewise, som as religion (translation 3) appears not to be a good translation of the English word 'religion' because som does not translate into other contextual understandings of the word. For instance, the idea of religion as an organized body with all its institutional structures, guiding scriptures and proselytizing tendencies is not quite applicable to the Akan cultural paradigm. As a result, som may not necessarily mean religion but represent ways in which Akan culture (and possibly different indigenous African cultures as well) tries to make sense of this Western culture called "religion." An objection may be raised about why, given the preceding statement, the title of this paper has "Akan religion" in it at all. Indeed, the paper is about aspects of Akan sacred beliefs and practices; but it is for want of a better expression that the beliefs and practices are presented as components of "Akan religion."

Onyankopon is also perceived in personal terms. The personality of Onyankopon is, for instance, implicit in the following appellations. Nana (Grand Ancestor), Abommubuwafre (Consoler), Jbsadee (Creator), Nyaamanekose (One in whom you confide when in trouble) [Opoku, 1978, p. 15]. In spite of all this, Onyankopon is regarded as a spirit. Religion is fundamental to the individual and the community, as God and other supernatural entities are believed to play important roles in the life of both the individual and the community. For instance, the powers of the deities (abosom) are sought for individual and communal protection, and libation is not even poured without the mention of God. But God, being personal, is portrayed in libation as one who understands prayers and grants the requests of humans. Moreover, the Akan would sometimes say Nana Nyame boa me! ("God help me!") when in need or difficulty. A deity, on the other hand, might give a charm to a person to serve some need. Similar roles are attributed to the deities and God in most African cultures, although there may be significant differences between theirs and the Akan's.

Consider Yoruba and Akan religions: Abioje holds the view that charms (or what he calls "occultic charms") in Yoruba thought enjoy the blessing of God; and he eventually comes to the conclusion that "occultic charm incantations also reflect a mark of divine revelation" (2007, p. 152). With his view on charms - especially those meant for evil purposes - Abioje was seeking to use the Biblical Isaiah's declaration (Isaiah 
45:7) about God as having revealed His nature as the author of both good and evil to claim that what is contained in Isaiah's message is neither new nor different from what adherents of Traditional Yoruba religion have always held about God. Abioje puts it more bluntly: "An informant put the argument to rest when he asked: 'Who made snakes and scorpions?' He said it was the same God who made sorcerers and witches” (2007, p. 152).

In Akan metaphysical thought, also, the deities who are the source of charms play very critical roles. Apart from their status, in Akan thought, as the next most potent beings after God, they are also regarded as intermediaries between humans and God. They are, like humans, creations of God and free. Their potency derives from God but they have autonomy and preferences (Gyekye, 1995, pp. 124-125). This is what makes it possible for them to use their powers in ways that do not promote the well-being of human beings, and in ways that God would not like. So, if someone consults a deity for a charm - or, if someone who has such a charm passes it on to another - with the intention of harming someone else and his wishes are fulfilled, the Akan would say to him that he has or his charms have the blessing of the originating deity. This is contrary to the Yoruba position that charms "enjoy the blessing of God". And, if "occultic charm connotes power, and a misuse of it represents abuse of power" (Abioje, 2007, pp. 153-154), then the difference is this: while in Yoruba thought responsibility for the abuse may ultimately be traced to God, only the user-recipient of the charm and the deity would be the abusers of power in Akan thought.

Quite related to the foregoing is the reference to the deities as "agents of God". Abioje asserts that "many adherents of the [Yoruba] religion maintain that all the divinities and spirits that are worshipped are agents of God" (Abioje, 2007, p. 150). This seems to imply that the divinities are representatives or that they act only at the bidding of God. In Akan thought, on the other hand, the divinities (abosom) are believed to (i) do things only occasionally on behalf of God, and (ii) do some things on behalf of human beings sometimes. If these make them agents, then they are agents of humans as well. ${ }^{4}$ Having discussed the concept of God in Akan thought - especially, the nature, worshippability, and personality of God - I now discuss the logical foundation of belief in God as found in some wise Akan sayings.

${ }^{4}$ I do not therefore support the prominent Akan philosopher, Kwasi Wiredu (1980) when he describes abosom as "agencies" of Onyankopon (God). See the chapter "Philosophy, Mysticism and Rationality." 


\section{Rationality of Akan Religion: Evidence from Wise Sayings}

The rationality of the Akan religion is, to some extent, inherent in some wise sayings of religious nature, especially those that seem to point to the rational origin of the Akan religion itself. But these sayings are unknown to many Western philosophers who continue not to see that some religions - in our case, Traditional Akan religion - could be rational.

It is well a discussed and established fact that Akan religion is natural. This being the case, it is also regarded as potentially comprehensible to every rational (human) being. This conception of the religion is also true of the Akan perspective on God. The maxim Obi nkyere akwadaa Nyame (literally, "Nobody needs show God to a child" [Sarpong, 1974, p. 9] or better still "Nobody teaches God to a child") appears to indicate their belief that the child, being a rational being, will come to the realization of God as he or she matures and, thus, gains more awareness of himself or herself, the environment, and the nature of the world. Accordingly, without any special revelation from God as such, Akan thinkers were able to postulate that God must be spiritual and everywhere. Confirming this position is the saying that Wo pese woka ascm kyere Nyame a, ka kyere mframa (literally, "If you want to say something to God, say it to the wind"). The thinking behind this is that although God is not perceptible, He has metaphysical presence everywhere, just as the wind/air is everywhere.

Another reason why the rational basis for Akan religion seems plausible is that there is indeed a concept of rationality in Akan thought. A statement or argument is regarded as irrational if it contains contradictions. But if it is devoid of contradictions and is logically acceptable, it is said of it Ets aso mu (literally, "It falls [well] into the ear"). But the capacity to determine which arguments or statements "fall well into the ear" is regarded as a human attribute, for, only humans are believed to have the capacity to think (dwen). This is the reason why the human capacity to self-know God and the nonexistence of missionary work are such important features of Akan religion.

Finally, the humanistic character of Akan religion provides for its rationality. The religion is humanistic because it thrives on interpersonal ethics (or relationships) and the exploitation of spiritual entities (or their powers) for human good on earth. The Akan thinker may then argue that if one seeks the promotion of human well-being, then, one should accept religion. This way, religion becomes rational to practice because it is contradictory to seek human well-being (on earth) and, at the same time, reject a humanistic religion. It would also be inappropriate to withhold or refuse to assist an afflicted person, especially if one is in a position to do otherwise. The refusal to help in such a situation would be deemed as inhuman, for it would be as if one was oblivious of the basic human condition, i.e., the human being requires and deserves to be helped. This human conceptual entitlement to help is expressed in the saying Onipa hia mmoa 
("the Human being needs help"). No individual is deemed to be self-sufficient. One is therefore encouraged to relate well to every human being with the love and kindness that one would offer to a brother or sister. This ultimately generates fellow-feeling - a notion which is captured in the saying Onipa nua ne 'nipa (meaning, "The sibling of a human being is a human being"). Thus, if by virtue of one's humanness, one ought to be treated kindly or humanely, it would be quite unreasonable if one should disregard the predicament of others. Another issue is that this might generate a situation where one would also be neglected by some in one's time of difficulty. [I do not imply that one ought to be neglected in such situations.]

However, if one wills or initiates evil against another, it is regarded in the Akan culture as both inhuman and self-destructive. It is also understood that one may act badly not necessarily by initiating evil action, but by refusing to stop an impending danger when one is in a position to do so (or has the duty to do so). This refusal to act is also seen as self-destructive. Indeed, this teaching is implicit in the maxim Jkomfobone se kuro mm $a$, stemu bi ("If a bad traditional priest wills that his town be ruined, he will live in it as well"). In other words, if the traditional priest who is supposed to intercede on behalf of the people refuses to do so, but rather vaticinates or invokes the powers of the deity for the destruction of the town, he cannot logically expect the town to be habitable for him as well.

The three maxims above together suggest that if one permits, wills, or initiates the destruction of another, one will eventually suffer some consequences too. This seems to underscore the reasonableness in seeing oneself in the Other and being supportive of one another for communal and personal good. In Akan culture, one is usually advised Wo ysnko da ne woda (literally, "Where your fellow human being lies is where you also lie" or "The situation your fellow human being finds him/her self in is what you [could] also find yourself in"). It suggests that the well-being of the community or humanity is not sought through selfish actions but by seeking the progress and interests of all. This way of ensuring the well-being of the community is always done in tandem with familial and communal performance of rites aimed at soliciting the help of the ancestors and deities. Such rites are usually performed on specific days of the week, festive occasions, and at public events. On the basis of the foregoing, the Akan thinker would advance that religion is not only useful, but it is rational to practice as well.

\section{Conclusion}

This paper has argued for the rationality of Traditional Akan religion, with special focus on the belief in God and on some Akan sayings. The idea of God and His role in the religious and communal life of the Akan have been shown to have developed on the basis of reflection - particularly, on the basis of some conceptions of rationality inherent 
in the Akan culture. In connection with this, some wise Akan sayings were explained. Also, since the supernatural (in this case, God) is an important element of Traditional Akan religion, this paper essentially is a presentation of the rationality of the supernatural in Akan metaphysical thought. 


\section{References}

Abioje, P. O. (2007). Divine revelation in African religion among the Yoruba and in Christianity. Legon Journal of the Humanities, XVIII, 145-158.

Busia, K. A. (1954). The Ashanti of the Gold Coast. In D. Forde (Ed.), African worlds (pp. 190-209). Oxford, UK: Oxford University Press.

Danquah, J. B. (1968). The Akan doctrine of God: A fragment of Gold Coast ethics and religion ( $2^{\text {nd }}$ ed.). London, UK: Frank Cass.

Gyekye, K. (1995). An essay on African philosophical thought: The Akan conceptual scheme (Rev. ed.). Philadelphia, PA: Temple University Press.

Gyekye, K. (1996). African cultural values: An introduction. Accra, Ghana: Sankofa.

Horton, R. (1960). A definition of religion, and its uses. Journal of the Royal Anthropological Institute of Great Britain and Ireland, 90 (2), 201-226.

Idowu, E. B. (1977). Olodumare: God in Yoruba belief. London, UK: Longman.

Jarvie, I. C. \& Agassi, J. (1977). The problem of the rationality of magic. In B. R. Wilson (Ed.), Rationality (pp. 172-193). Oxford, UK: Basil Blackwell.

Opoku, A. K. (1978). West African traditional religion. Accra, Ghana: F. E. P. International.

Oso, S. O. (1979). Lectures on West African traditional religion. Ado-Ekiti, Nigeria: Bamgboye.

Sarpong, P. (1974). Ghana in retrospect: Some aspects of Ghanaian culture. Tema, Ghana: Ghana Publishing Corporation.

Soyinka, W. (2004). The burden of memory, the muse of forgiveness. In N. Scheper-

Hughes and P. I. Bourgois (Eds.), Violence in war and peace: An anthology (pp. 475-477). Malden, UK: Blackwell.

Wiredu, K. (1980). Philosophy and an African culture. Cambridge, UK: Cambridge University Press. 